\title{
MsSAMS, A Cold Stress-responsive Gene, Imparts Resistance to Environmental Stress Even in T2 Generation Transgenic Plants
}

Hye Lim Choi

Kangwon National University

Ji Won Seo

Kangwon National University

Myeong Ha Hwang

Kangwon National University

Chang Yeon Yu

Kangwon National University

Eun Soo Seong ( $\nabla$ eunsooses@swc.ac.kr)

Suwon Women's University

\section{Research Article}

Keywords: MsSAMS, T2 generation transgenic plants, Cold stress, Drought stress, Oxidative stress

Posted Date: February 9th, 2021

DOl: https://doi.org/10.21203/rs.3.rs-177515/v1

License: (c) (i) This work is licensed under a Creative Commons Attribution 4.0 International License. Read Full License 


\section{Abstract}

This study was conducted to test the expression of the MsSAMS (Miscanthus sinensis Sadenosylmethionine synthetase) gene of $\mathrm{T}_{2}$ generation transgenic plants and to investigate their resistance and functionality to various environmental stresses. SEM (Scanning electron microscopy) revealed that the thickest leaves were from the T6 transgenic line, at $161.24 \pm 8.05 \mu \mathrm{m}$. Resistance to various factors such as low temperature, drought, and oxidative stress in the $T_{2}$ generation transgenic plants was also confirmed. Under cold stress conditions, the T6 transgenic line showed the lowest value $(22.73 \%)$ of ion leakage, and under drought stress conditions, the transgenic lines showed lower ion leakage compared to the control after treatment with any concentration of mannitol. Even under oxidative stress conditions, transgenic plants showed lower ion leakage levels compared to the control after treatment with all concentrations of methyl viologen. Regarding SAMS enzyme activity, as the time of cold treatment increased, the transgenic plants showed a tendency to decrease and then increase (22.75 $\pm 1.95 \mathrm{mg} / \mathrm{g}-\mathrm{FW}$ ). Based on these results, it was suggested that the MsSAMS gene induced by cold stress can serve as a marker showing diversity of responding to environmental stresses because resistance to cold damage and various environmental stresses are stably inherited by the $T_{2}$ generation.

\section{Introduction}

Environmental stress limits the overall growth and yield of crops worldwide. The resistance and adaptation of plants to environmental stress are a result of the transcriptional expression of stressresponsive genes. Plant breeders currently exert much effort in improving crop tolerance to environmental stresses, such as climatic change and pollution [1]. One positive approach against environmental problems is through studying the development of stress-tolerant crops [2].

S-adenosylmethionine synthetases (SAMSs) are involved in the biosynthetic pathways of ethylene, overall plant development, and the stress response [3]. Ethylene is considered a stress-responsive hormone regulating plant growth and development [4]. SAMS (S-adenosylmethionine synthetase) is an enzyme that participates in the methylation reaction, and the accumulation of SAMS in plants is involved in development and the response to environmental stress [5]. The SAMS gene was isolated from Arabidopsis, rice, ginseng, Chinese cabbage, black locust, potatoes, beans, and cucumbers [6-13]. Some studies have reported the functions of SAMS related to abiotic stress tolerance in Nicotiana tabacum and Medicago sativa $[14,15]$. In this way, they can be regarded as a target to improve tolerance against abiotic stress in plants. However, there is no report regarding the resistance phenotype against abiotic stress of the SAMS gene appearing stably until the $\mathrm{T}_{2}$ generation. In a previous study, the MSSAMS gene was isolated from wintering Miscanthus and inserted into $N$. benthamiana to produce transgenic plants whose $T_{1}$ generations were resistant against low temperatures [16].

Nicotiana benthamiana is highly susceptible to animal and plant viruses, has a shorter lifespan than other Solanaceae, and is suitable for use as a model plant because it produces a large number of seeds $[17,18]$. In addition, a study by Hann and Rathjen [19] reported that a plant defense response was elicited 
by expressing the flagellum protein of Pseudomonas syringae in $N$. benthamiana. Human vaccine studies unveiled the potential for plants acting as bioreactors, after the successful production of the Ebola immune complex (EIC) [20]. Metabolic engineering studies on the synthesis and accumulation of glycerolipids and medium-chain fatty acids (MCFA) were also conducted on these plants [21, 22]. As such, $N$. benthamiana has been used as a model plant in various fields of research, such as molecular plant-microbial interaction, metabolic pathways, vaccine production, and synthetic biology.

In this study, the MSSAMS gene was inserted was amplified in the $\mathrm{T}_{2}$ generation of $N$. benthamiana, the MSSAMS gene was analyzed, and morphological characterization and investigation of plant growth were performed until the $\mathrm{T}_{2}$ generation of transgenic plants. In addition, the physiological characteristics of the stomata and the leaf thickness of the transformants were compared using electron microscopy analysis. The degree of resistance to environmental stress in the $T_{2}$ generation transgenic plants and the association with the SAMS enzyme activity were also examined.

\section{Materials And Methods}

\section{Progeny propagation for $\mathrm{T}_{2}$ generation of transgenic plants}

The seeds of the $T_{1}$ transgenic plants produced by Seong et al. [16] were stored at $4{ }^{\circ} \mathrm{C}$, and then sown in a plant growth chamber (Fig. 1a). Transformed $\mathrm{T}_{1}$ seeds of $N$. benthamiana were placed in MS medium containing $25 \mu \mathrm{g} / \mathrm{mL}$ kanamycin. After acclimatization, the $T_{1}$ generation transgenic plants were incubated under light conditions at $25 \pm 3^{\circ} \mathrm{C}$ for $16 \mathrm{~h}$ (Fig. 1b). $\mathrm{T}_{2}$ generation transgenic seeds were obtained 4 weeks after sowing.

\section{Molecular characterization of $\mathrm{T}_{2}$ generation transgenic plants}

Genomic DNA analysis and RT-PCR were performed using fresh leaves of $\mathrm{T}_{2}$ generation transgenic plants grown for 4 weeks or longer, including controls. Genomic DNA and total RNA were extracted according to the method described by Seong et al. [16]. cDNA was synthesized from total RNA using M-MLV RT, amplified by PCR using MsSAMS primer, and the bands were confirmed by electrophoresis on a $1 \%$ agarose gel (Table 1). The PCR conditions were as follows: $1 \mathrm{~min}$ at $94^{\circ} \mathrm{C}, 35$ cycles for $1 \mathrm{~min}$ at $94^{\circ} \mathrm{C}, 1$ min at $58^{\circ} \mathrm{C}$, and $1 \mathrm{~min}$ at $72^{\circ} \mathrm{C}$, and $10 \mathrm{~min}$ at $72^{\circ} \mathrm{C}$. The RT-PCR conditions are as follows: $1 \mathrm{~min}$ at $94^{\circ} \mathrm{C}$, and then 30 cycles for $1 \mathrm{~min}$ at $94^{\circ} \mathrm{C}, 1 \mathrm{~min}$ at $58^{\circ} \mathrm{C}$ and $1 \mathrm{~min}$ at $72^{\circ} \mathrm{C}$ for extension, and $10 \mathrm{~min}$ at $72^{\circ} \mathrm{C}$. The primers used for molecular analysis in $\mathrm{T}_{2}$ generation transgenic plants was forward (5'GGGTCTAGAATGTTTGGGTA - 3') and reverse (5'- GGGGAGCTCTTAGGCAGAAG - 3') of MsSAMS and forward (5'- CAGCTCATCCGTGGAGAAGA - 3') and reverse (5'- AGGATACGGGGAGCTAATGC - 3') of NbActin. 
Table 1

Differentiation of leaf thickness by scanning electron microscopy (SEM) images between non-transgenic and T2 generation transgenic plants.

\begin{tabular}{|c|c|}
\hline Plant & Leaf thickness $(\mathbb{\nabla})$ \\
\hline NT & $67.12 \pm 3.22^{\mathrm{e}}$ \\
\hline T1 & $99.54 \pm 3.58^{c}$ \\
\hline T2 & $115.94 \pm 10.53^{b}$ \\
\hline T6 & $161.24 \pm 8.05^{\mathrm{a}}$ \\
\hline T9 & $101.32 \pm 8.09^{c}$ \\
\hline T17 & $87.23 \pm 2.34^{d}$ \\
\hline
\end{tabular}

\section{Morphological characterization of $\mathrm{T}_{2}$ generation transgenic plants via SEM}

The fourth and fifth leaves from the top of the control and transgenic plants grown in a greenhouse for 10 weeks were used. After reaction at $4{ }^{\circ} \mathrm{C}$ for $24 \mathrm{~h}$ using a fixative solution containing $2 \%$ glutaraldehyde and $2 \%$ paraformaldehyde, leaves were washed 3 times for 10 min each with phosphate buffered saline (PBS). The leaves were then dehydrated with ethanol (50,60, 70, 80, 90 and 100\%) for 30 min each, respectively, then transferred to a mixture of ethanol and isoamyl acetate $(2: 1,1: 1,1: 2$, and $0: 1 \mathrm{v} / \mathrm{v}, 30$ min each, in that order). They were then dried at $20^{\circ} \mathrm{C}$ for $20 \mathrm{~min}$ and at $35^{\circ} \mathrm{C}$ for 5 min using a critical point dryer. The dried tissue was observed using a Variable Pressure Field Emission Scanning Electron Microscope (VP-FE-SEM) (KBSI, Chuncheon, Korea).

\section{Test of ion leakage of $\mathrm{T}_{2}$ generation transgenic plants under environmental stresses}

Leaves of $T_{2}$ generation transgenic plants and controls were punched, five leaves thick, with a punch of diameter $1.0 \mathrm{~cm}$, and the ion leakage was measured. To test the rate of ion leakage against cold stress, the sample was placed in $5 \mathrm{~mL}$ of distilled water and treated at $2 \pm 1{ }^{\circ} \mathrm{C}$ for $24 \mathrm{~h}$. To measure the rate of ion leakage against drying and oxidative stress, samples were placed in $5 \mathrm{~mL}$ of mannitol $(0,20,50$, and $100 \mathrm{mM}$ ) and methyl viologen (MV) at $0,2.5$, and $5 \mu \mathrm{M}$, respectively, and treated under dark conditions for 
$24 \mathrm{~h}$. Conductivity was measured and calculated as a percentage using an electrical conductivity measuring device (Conductivity/Salinity Meter EC-400L).

\section{Measurement of SAMS activity}

The method of Wang et al. [12] was modified to measure the expression of the SAMS enzyme. About 0.1 $\mathrm{g}$ leaves (control and transgenic plants) were frozen with liquid nitrogen and homogenized with a buffer containing $50 \mathrm{mM}$ Tris-HCl, $1 \mathrm{mM}$ EDTA, 2\% polyvinylpyrrolidone, $5 \mathrm{mM}$ 2-mercaptoethanol, and $10 \mathrm{mM}$ $\mathrm{MgCl}_{2}$ (pH 7.6). After centrifugation at $4{ }^{\circ} \mathrm{C}$ at $10,000 \mathrm{rpm}$ for $20 \mathrm{~min}$, the supernatant was collected to measure the protein concentration according to the method reported by Bradford [23]. A reaction solution (pH 8.0) was prepared by mixing $100 \mathrm{mM}$ Tris- $\mathrm{HCl}, 20 \mathrm{mM} \mathrm{MgCl}_{2}, 150 \mathrm{mM} \mathrm{KCl}, 5 \mathrm{mM}$ dithiothreitol, $2 \mathrm{mM}$ ATP, and $1 \mathrm{mM}$ methionine. One hundred microliters of the supernatant and $900 \mu \mathrm{L}$ of the reaction solution were mixed and reacted for 20 min under dark conditions at room temperature, then Bradford reagent (Sigma Aldrich, USA) was added and reacted at room temperature for $5 \mathrm{~min}$. Absorbance was measured at $620 \mathrm{~nm}$ using a UV-spectrophotometer, and the protein content was measured using a calibration curve calculated using bovine serum albumin as a standard.

\section{Results}

\section{$\mathrm{T}_{2}$ generation transgenic plants overexpressing MsSAMS gene increase to leaf thickness, size and number of stomata}

Genomic DNA was extracted from the control and $\mathrm{T}_{2}$ generation transgenic plants of $N$. benthamiana grown in a medium containing kanamycin, confirming the successful insertion of the MsSAMS gene. A distinct band (804 bp) was confirmed in all transgenic plants of the $\mathrm{T}_{2}$ generation, except for the control (Fig. 1c). cDNA synthesis also confirmed that the MsSAMS gene was not expressed in the control, but the highest expression levels were found in the T6, T2, and T9 lines (Fig. 1d). There was a difference in the level of transcriptional expression of the MSSAMSgene among the transgenic plants.

Leaf thickness measurement using SEM revealed that the thinnest leaves measured $67.12 \pm 3.22 \mu \mathrm{m}$ thick in the control, while the thickest was $161.24 \pm 8.05 \mu \mathrm{m}$ from the T6 transgenic line (Fig. 2a-f; Table 1). The number of stomata was measured under a microscope, with a magnification of $100 \mu \mathrm{m}$. The number of pores in the control was the lowest at $15.33 \pm 0.58$, followed by T1 ( $34.00 \pm 1.00), T 6$ $(33.33 \pm 5.51)$, and T9 $(32.33 \pm 0.58)$ transgenic lines. The stoma size was also the smallest in the control $(24.15 \pm 2.93 \mu \mathrm{m}$ in length and $20.33 \pm 0.62 \mu \mathrm{m}$ in width), while it was largest in the T2 transgenic line (34.35 $\pm 3.45 \mu \mathrm{m}$ in length and $26.02 \pm 1.85 \mu \mathrm{m}$ in width) (Table 2). In addition, the stomata of the control were almost closed, while most of those in the transgenic plants were open. 
Table 2

Morphological analysis of stomata by scanning electron microscopy (SEM) images between nontransgenic and $\mathrm{T} 2$ generation transgenic plants.

\begin{tabular}{|c|c|c|c|c|c|}
\hline \multirow[t]{3}{*}{ Plant } & \multicolumn{4}{|l|}{ Stoma size $(\mathbb{\nabla})$} & \multirow[t]{3}{*}{ Number of stoma } \\
\hline & \multicolumn{2}{|l|}{ Outside } & \multicolumn{2}{|l|}{ Inside } & \\
\hline & Length & Width & Length & Width & \\
\hline NT & $24.15 \pm 2.93^{c}$ & $20.33 \pm 0.62^{c}$ & $5.02 \pm 0.75^{d}$ & $1.21 \pm 0.29^{d}$ & $15.33 \pm 0.58^{c}$ \\
\hline T1 & $27.56 \pm 1.96^{b c}$ & $22.31 \pm 0.53^{b c}$ & $12.97 \pm 1.26^{\mathrm{C}}$ & $3.28 \pm 0.83^{c}$ & $34.00 \pm 1.00^{a}$ \\
\hline $\mathrm{T} 2$ & $34.35 \pm 3.45^{\mathrm{a}}$ & $26.02 \pm 1.85^{\mathrm{a}}$ & $20.93 \pm 1.02^{\mathrm{a}}$ & $8.25 \pm 1.12^{\mathrm{a}}$ & $23.67 \pm 3.79^{b}$ \\
\hline T6 & $28.42 \pm 1.82^{b c}$ & $23.88 \pm 1.79^{a b}$ & $14.70 \pm 2.31^{b c}$ & $5.58 \pm 1.36^{b}$ & $33.33 \pm 5.51^{\mathrm{a}}$ \\
\hline T9 & $25.39 \pm 1.66^{c}$ & $20.50 \pm 1.07^{c}$ & $12.08 \pm 2.01^{\mathrm{c}}$ & $4.13 \pm 1.19^{b c}$ & $32.33 \pm 0.58^{a}$ \\
\hline T17 & $31.01 \pm 3.08^{\mathrm{ab}}$ & $21.14 \pm 1.02^{c}$ & $17.30 \pm 1.22^{b}$ & $4.35 \pm 0.73^{b c}$ & $20.00 \pm 2.65^{b c}$ \\
\hline
\end{tabular}

\section{$\mathrm{T}_{2}$ generation transgenic plants overexpressing MsSAMS gene cause resistance to cold, drought, and oxidative stresses}

At low temperatures, transgenic plants showed a lower ion leakage, with the lowest leakage observed in the T6 line (22.73\%) (Fig. 3a), about half that of the control. This was consistent with the results obtained by Seong et al. [16], who examined the recovery rate of the control and $T_{1}$ generation transgenic plants under cold stress. Mannitol, which causes water damage, was used to examine drought resistance [24]. Transgenic plants showed a lower ion leakage than the control, with the ion leakage decreasing with increasing mannitol concentration. The T6 transgenic line showed the lowest ion leakage after treatment with mannitol concentration, and was found to have the highest drought resistance. The ion leakage of this line under mannitol stress was $30.24 \pm 0.26 \%$ at $0 \mathrm{mM}, 27.66 \pm 1.73$ at $20 \mathrm{mM}, 27.23 \pm 1.49 \%$ at 50 $\mathrm{mM}$, and $19.42 \pm 1.85 \%$ at $100 \mathrm{mM}$ (Fig. 3b). Methyl viologen (MV), a herbicide, was used to measure resistance to oxidative stress. After treatment with increasing concentrations of $\mathrm{MV}$, the higher ion leakage was observed, with the T2 transgenic plants showing lower values than the control. Treatment with $5 \mu \mathrm{M}$ MV showed $38.82 \pm 1.3 \%$ ion leakage in the T2 transgenic line, which was selected as the transgenic line showing the strongest resistance to oxidative stress (Fig. 3c). 


\section{Activity of SAMS enzyme involved in the tolerance of environmental stresses}

The highest protein content $(22.75 \pm 1.95 \mathrm{mg} / \mathrm{g}$ - FW) was obtained in the T6 transgenic line after $48 \mathrm{~h}$ of cold treatment, which was about 4 times higher than that of the control $(5.90 \pm 1.81 \mathrm{mg} / \mathrm{g}-\mathrm{FW})$ (Fig. $3 \mathrm{~d})$. This result showed similar results to the MSSAMS gene expression level in the previous experiment, and was consistent with the results of the correlation survey.

\section{Discussion}

In a study by Seong et al. [24], it was found that the leaf thickness of transgenic plants containing environmental stress resistance genes was thicker than that of the control. Another report showed potato plants with thicker leaves and high lignin content, which is involved in oxidative stress resistance in comparison to the control [25]. In the report of Jia et al. [26], it was confirmed that lignin is an important component of the cell wall; as the concentration of lignin increases, the cell wall thickness increases, and it affects plant tissues. Therefore, leaf thickness and PAL expression related to the lignin biosynthesis gene were considered to have a significant correlation.

In a study by Choi et al. [27], it was confirmed that transgenic chrysanthemum plants containing a lowtemperature resistance gene had larger stoma sizes than non-transgenic controls, and that the stomata remained open when the plants were subject to low temperatures. It was confirmed that plant species adapted to a low temperature and humid environment, such as in the shade, maintaining large, open stomata [28]. Therefore, the maintenance of large, open stomata in transgenic plants from this study was considered to be a characteristic that promotes the diffusion of $\mathrm{CO}_{2}$ at low temperatures, improving photosynthesis. When plants are exposed to various stresses, the structure of their tissues, especially the plasma membrane, are destroyed, and the electrolytes stored in the cell are released. At this time, the degree of damage due to stress in the plant tissue can be measured by measuring and comparing the amount of emerging electrolytes [29].

In the study of Guo et al. [30], ion leakage of control and transgenic plants were treated with cold stress at $3^{\circ} \mathrm{C}$, similar to that of this study. Therefore, it was believed that transgenic expression of the SAMS gene in plants imparted a higher resistance to cold stress compared to non-transgenic controls. When mannitol was added to the MSSAMS-containing transgenic seeds, they showed a superior germination rate than the control [16]. In this experiment, it was thought that drought tolerance increased due to the expression of the MSSAMS gene, which showed less ion leakage with increasing mannitol concentration. The result of MV treatment is consistent with the fact that the expression level of the MSSAMS gene was highest in the T2 and T6 transgenic lines. When transgenic plants containing the Lebzip2 gene were treated with $M V$, the rate of ion loss was lower than that of the control [24]. Here, it was confirmed that $T_{2}$ generationtransgenic plants containing the MSSAMS gene were resistant to drought, cold, and oxidative stress. 
SAMS is an enzyme that uses ATP and methionine to catalyze the biosynthesis of SAM. To examine its enzyme activity, the SAMS enzyme was extracted from the control and transgenic plants, and the amount of SAM formed after reacting with adenosine 5 '-triphosphate (ATP) and methionine was quantified via the Bradford assay. The Bradford assay is a method of quantifying proteins by measuring their absorbance after reacting with Coomassie brilliant blue. The SAM content of the control showed a tendency to decrease with cold treatment; while in transgenic plants, the SAM content decreased after 24 $\mathrm{h}$ of cold treatment, but increased again after $48 \mathrm{~h}$. This trend was consistent with the results of Wang et al. [12], which was thought to be a result of the time difference in which genes are expressed during cold treatment. The result of SAM content was measured in the control and the values were measured at $0 \mathrm{~h}$ for all samples was thought to be the result of the reaction of free methionine-rich proteins to the reagent compared to SAM [31-33].

\section{Conclusion}

This study showed the production of transgenic plant with resistance to various environmental stresses using SAMS gene. The focus of this study is an experiment using $\mathrm{T}_{2}$ generation-transgenic plants. Through all the results, the SAMSgene was stably inherited up to the $\mathrm{T}_{2}$ generation, and they were consistent with the $T_{1}$ generation phenotype even in the $T_{2}$ generation. The contents of the results revealed the relationship between the resistance to various environmental stresses through the phenotype at the cellular level for $\mathrm{T}_{2}$ generation- transgenic plants and the association with the SAM enzyme. Therefore, SAMS gene may also be introduced into other crops in the future to reduce various abiotic stress damages and increase function for resistance.

\section{Declarations}

\section{Acknowledgements}

This study was supported by the Bioherb Research Institute, Kangwon National University, Republic of Korea.

\section{Author contributions}

Contribution of experiment (HLC); Contribution of experimental assist (JWS, MHH); Analysis of data and interpretation (CYY); performed the experiment and wrote the paper (ESS).

\section{Compliance with ethical standards}

\section{Conflict of interest}


The authors declare that they have no conflict of interest.

\section{Research involving human participants and/or animals}

This article doew not contain any studies with human participants or animals performed by any of the authors.

\section{References}

1. Altieri MA, Nicholls $\mathrm{Cl}$ (2017) The adaptation and mitigation potential of traditional agriculture in a changing climate. Clim Chang 140:33-45

2. Fita A, Rodríguez-Burruezo A, Prohens J, Vicente O (2015) Breeding and Domesticating Crops Adapted to Drought and Salinity: A New Paradigm for Increasing Food Production. Front Plant Sci 6:978

3. Ding B, Chen T, Yang Y, Liu S, Yan K, Yue X, Zhang H, Xiang Y, An L, Chen S (2015) Molecular cloning and characterization of an S-adenosylmethionine synthetase gene from Chorispora bungeana. Gene 572:205-213

4. Harpaz-Saad S, Yoon GM, Mattoo AK, Kieber JJ (2012) The formation of ACC and competition between polyamines and ethylene for SAM. Annu Plant Rev 44:53-81

5. He M, Wang Y, Wu J, Shu S, Sun J, Guo S (2019) Isolation and characterization of Sadenosylmethionine synthase gene from cucumber and responsive to abiotic stress. Plant Physiol Biochem 141:431-445

6. Peleman J, Saito K, Cottyn B, Engler G, Seurinck J, Van Montagu M, Inzé D (1989) Structure and expression analyses of the S-adenosylmethionine synthetase gene family in Arabidopsis thaliana. Gene 84:359-369

7. Lee JH, Chae HS, Lee JH, Hwang B, Hahn KW, Kang BG, Kim WT (1997) Structure and expression of two cDNAs encoding S-adenosyl-L- methionine synthetase of rice (Oryza sativa). Biochim. Biophysic. Acta (BBA)-Gene Struc Express 1354:13-18

8. Pulla RK, Kim Y, Parvin S, Shim J, Lee J, Kim Y, In J, Senthil KS, Yang D (2009) Isolation of Sadenosyl-L-methionine synthetase gene from Panax ginseng CA meyer and analysis of its response to abiotic stresses. Physiol Mol Biol Plants 15:267-275

9. Yu JG, Lee GH, Park YD (2012) Physiological role of endogenous S-adenosyl-L-methionine synthetase in chinese cabbage. Hort Environ Biotech 53:247-255

10. Quan J, Zhang S, Zhang C, Meng S, Zhao S, Xu X (2014) Molecular cloning, characterization and expression analysis of the SAMS gene during adventitious root development in IBA-induced tetraploid black locust. PloS One 9:e108709

11. Kim SH, Kim SH, Palaniyandi SA, Yang SH, Suh J (2015) Expression of potato S-adenosyl-Lmethionine synthase (SbSAMS) gene altered developmental characteristics and stress responses in 
transgenic Arabidopsis plants. Plant Physiol Biochem 87:84-91

12. Wang X, Oh M, Komatsu S (2016) Characterization of S-adenosylmethionine synthetases in soybean under flooding and drought stresses. Biol Plant 60:269-278

13. Wang L, He M, Guo S, Zhong M, Shu S, Sun J (2017) NaCl stress induces CsSAMs gene expression in Cucumis sativus by mediating the binding of CsGT-3b to the GT-1 element within the CsSAMs promoter. Planta 245:889-908

14. Qi YC, Wang FF, Zhang H, Liu WQ (2010) Overexpression of Suaeda salsa S-adenosylmethionine synthetase gene promotes salt tolerance in transgenic tobacco. Acta Physiol Plant 32:263-269

15. Uvá cková L, Taká `c T, Boehm N, Obert B, Šamaj J (2012) Proteomic and biochemical analysis of maize anthers after cold pretreatment and induction of androgenesis reveals an important role of anti-oxidative enzymes. J Proteom 75:1886-1894

16. Seong ES, Jeon MR, Choi JH, Yoo JH, Lee JG, Na JK, Kim NY, Yu CY (2020) Overexpression of Sadenosylmethionine Synthetase Enhances Tolerance to Cold Stress in Tobacco. Russ Plant Physiol 67:242-249

17. Dasgupta R, Garcia BH, Goodman RM (2001) Systemic spread of an RNA insect virus in plants expressing plant viral movement protein genes. Proceed Nat Acad Sci USA 98:4910-4915

18. Goodin MM, Zaitlin D, Naidu RA, Lommel SA (2008) Nicotiana benthamiana: Its history and future as a model for plant-pathogen interactions. Mol Plant-Microbe Inter 21:1015-1026

19. Hann DR, Rathjen JP (2007) Early events in the pathogenicity of Pseudomonas syringae on Nicotiana benthamiana. The Plant J 49:607-618

20. Phoolcharoen W, Bhoo SH, Lai H, Ma J, Arntzen CJ, Chen Q, Mason HS (2011) Expression of an immunogenic ebola immune complex in Nicotiana benthamiana. Plant Biotech J 9:807-816

21. Naim F, Nakasugi K, Crowhurst RN, Hilario E, Zwart AB, Hellens RP, Taylor JM, Waterhouse PM, Wood CC (2012) Advanced engineering of lipid metabolism in Nicotiana benthamiana using a draft genome and the V2 viral silencing-suppressor protein. PLoS One 7:e52717

22. Reynolds KB, Taylor MC, Zhou X, Vanhercke T, Wood CC, Blanchard CL, Singh SP, Petrie JR (2015) Metabolic engineering of medium-chain fatty acid biosynthesis in Nicotiana benthamiana plant leaf lipids. Front Plant Sci 6:Article164

23. Bradford MM (1976) A rapid and sensitive method for the quantitation of microgram quantities of protein utilizing the principle of protein-dye binding. Anal Biochem 72:248-254

24. Seong ES, Yoo JH, Kim NJ, Choi JH, Lee JG, Ghimire BK, Chung IM, Yu CY (2016) Morphological changes and increase of resistance to oxidative stress by overexpression of the LebZIP2 gene in Nicotiana benthamiana. Russ J Plant Physiol 63:124-131

25. Park HJ, Lee A, Lee SS, An D, Moon K, Ahn JC, Kim H, Cho HS (2017) Overexpression of golgi protein CYP21-4s improves crop productivity in potato and rice by increasing the abundance of mannosidic glycoproteins. Front Plant Sci 8:1250 
26. Jia XL, Wang GL, Xiong F, Yu XR, Xu ZS, Wang F, Xiong AS (2015) De novo assembly, transcriptome characterization, lignin accumulation, and anatomic characteristics: Novel insights into lignin biosynthesis during celery leaf development. Sci Rep 5:8259

27. Choi IY, Han SG, Kang CH, Song YJ, Lee WH (2008) The characterization of transgenic chrysanthemum under low temperature condition. J Plant Biotechnol 35:55-61

28. Hetherington AM, Woodward FI (2003) The role of stomata in sensing and driving environmental change. Nature 424:901-908

29. Saltveit ME (2002) The rate of ion leakage from chilling-sensitive tissue does not immediately increase upon exposure to chilling temperatures. Post Biol Technol 26:295-304

30. Guo Z, Tan J, Zhuo C, Wang C, Xiang B, Wang Z (2014) Abscisic acid, $\mathrm{H}_{2} \mathrm{O}_{2}$ and nitric oxide interactions mediated cold-induced S-adenosylmethionine synthetase in Medicago sativa subsp. falcata that confers cold tolerance through up regulating polyamine oxidation. Plant Biotech $\mathrm{J}$ 12:601-612

31. Machado Neto NB, Saturnino SM, Bomfim DC, Custódio CC (2004) Water stress induced by mannitol and sodium chloride in soybean cultivars. Brazil Arch Biol Technol 47:521-529

32. Wallsgrove RM, Lea PJ, Miflin BJ, Intracellular localization of aspartate kinase and the enzymes of threonine and methionine biosynthesis in green leaves. Plant Physiol 71:780-784

33. Finkelstein JD (1990) Methionine metabolism in mammals. J Nut Biochem 1:228-237

\section{Figures}


Fig. 1

(a)

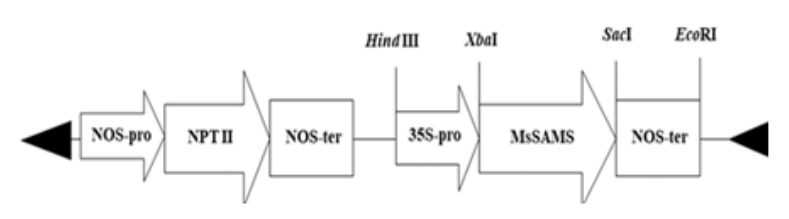

(b)

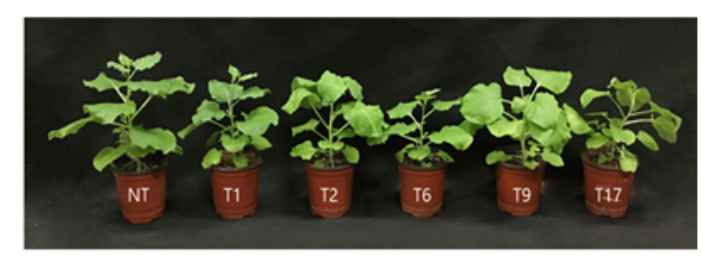

(c)

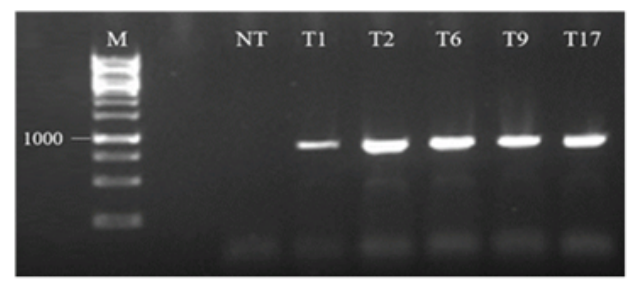

(d)

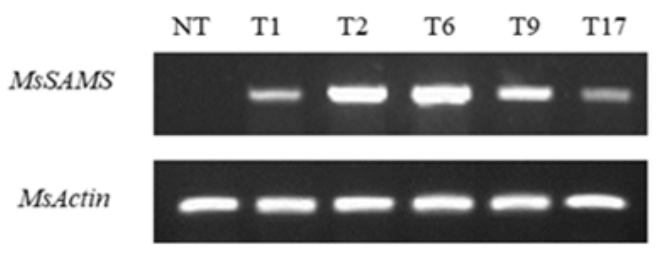

\section{Figure 1}

Molecular characterization between non-transgenic and T2 generation transgenic plants overexpressing MsSAMS gene. (a) Schematic presentation of MsSAMS cloned into plant expression vector pMBP1 by Seong et al. (2020). (b) Production of non-transgenic and T2 transgenic plants. (c) Detection of genomic DNA of T2 transgenic plants. M: $1 \mathrm{~kb}$ ladder marker; NT: non-transgenic plant; T1, T2, T6, T9, T17: transgenic plants. (d) Expression level of MsSAMS gene of T2 transgenic plants through RT-PCR. 
Fig. 2
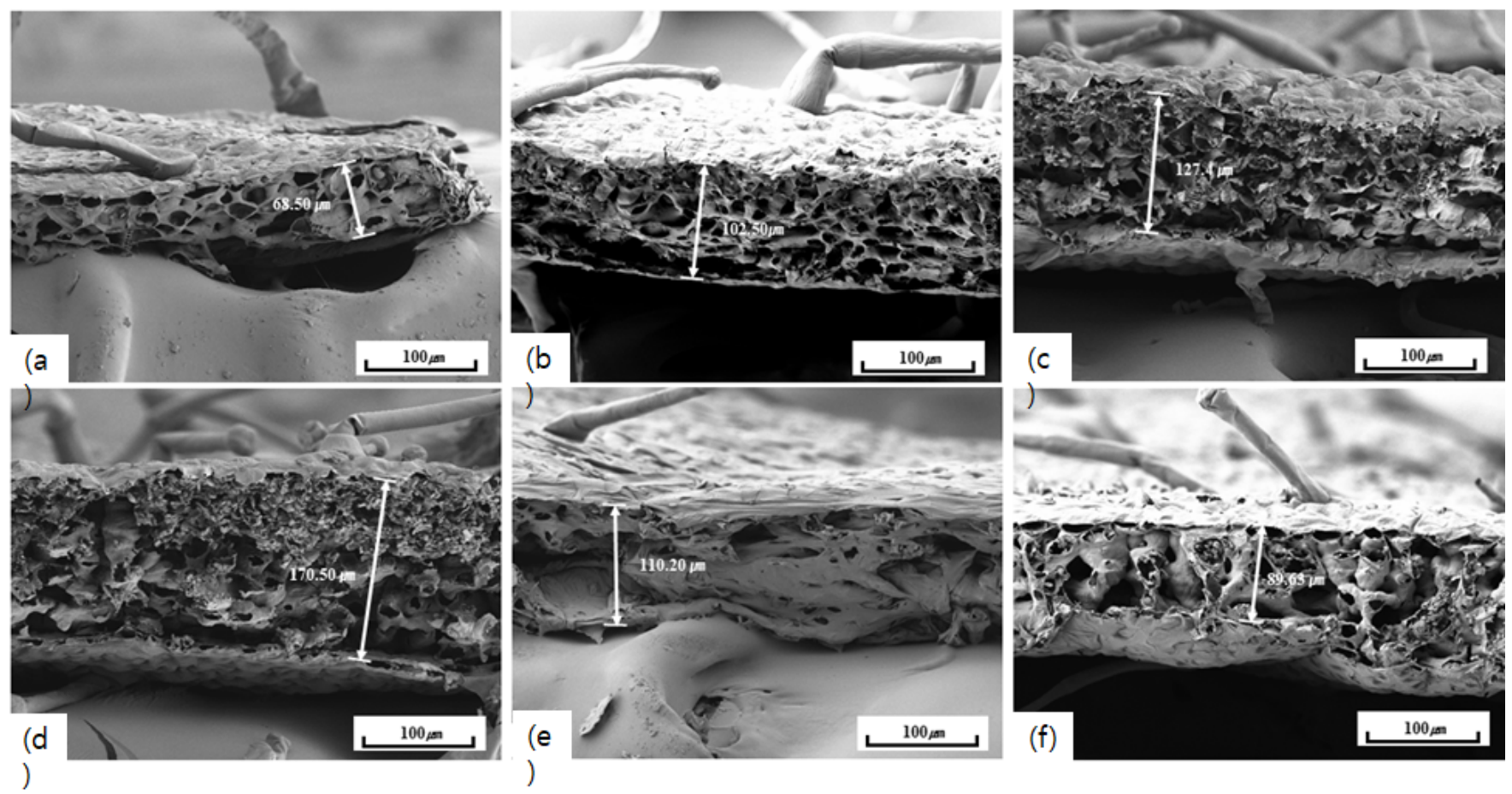

Figure 2

Morphological difference of leaf thickness by scanning electron microscopy images (SEM) between nontransgenic and T2 generation transgenic plants overexpressing MsSAMS gene. (a) non-transgenic plant; (b-f) T2 generation transgenic plants.

Fig. 3

(a)

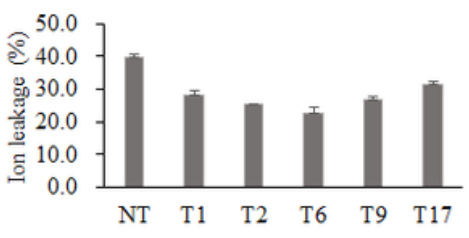

(b)

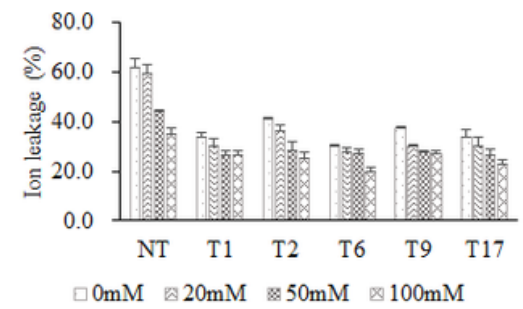

(c)

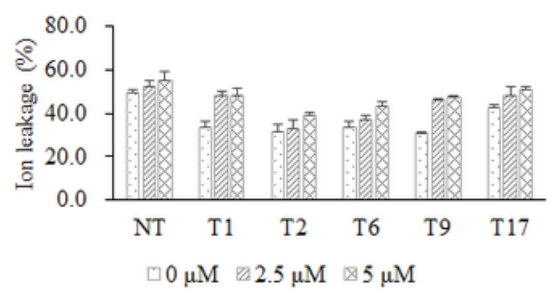

(d)

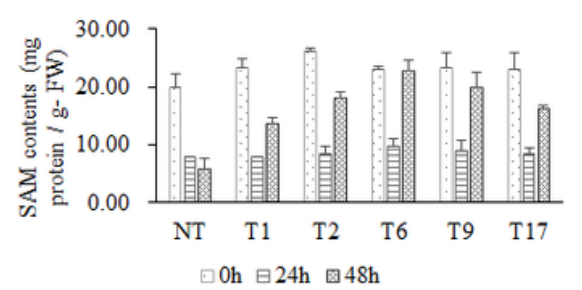




\section{Figure 3}

Ion leakage rate of non-transgenic under various environmental stress treatments for 24 hours and SAM (s-adenosylmethionine) contents under cold treatments for 24 and 48 hours in T2 generation transgenic plants. NT: non-transgenic; T1-T17: T2 generation transgenic lines. (a) cold treatment; (b) mannitol treatment; (c) methyl viologen treatment; (d) SAM content. FW: Fresh weight. 